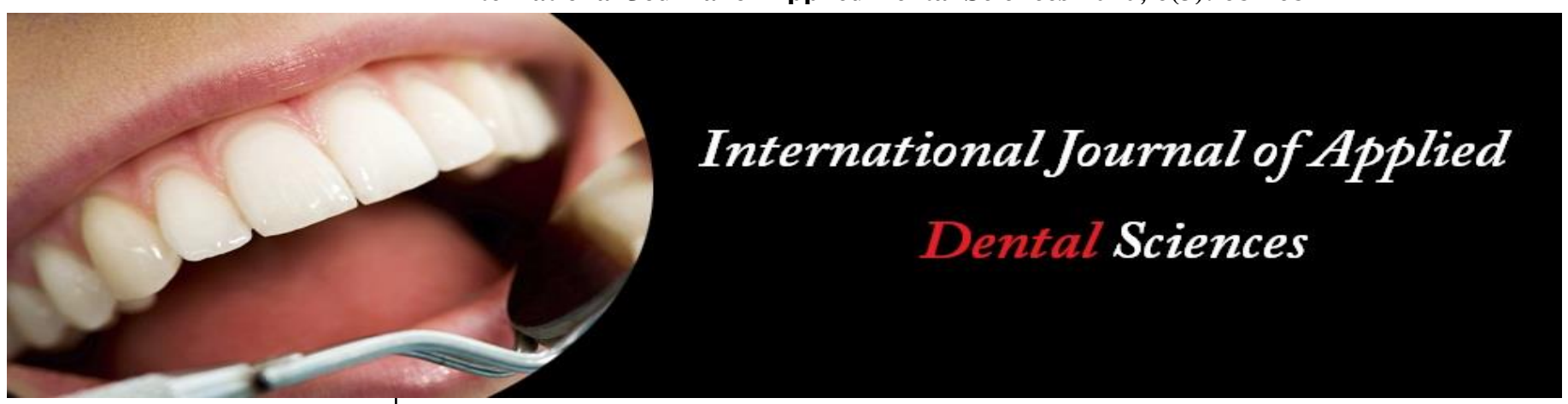

ISSN Print: 2394-7489

ISSN Online: 2394-7497

IJADS 2020; 6(3): 684-687

(C) 2020 IJADS

www.oraljournal.com

Received: 24-05-2020

Accepted: 26-06-2020

Dr. Hala Sala Aldeen Alshakaki PhD. Student, Department of

Removable Prosthodontics,

Faculty of Dentistry, Hama

University, Syria

Dr. Hussein Ali Al-Essa

Assistant professor in

Department of conservative

dentistry \& removable

prosthodontics, Faculty of

Dentistry, Hama University,

Dean of the faculty of dentistry

in Al-Wataniya Private

University, Hama, Syria

Corresponding Author:

Dr. Hala Sala Aldeen Alshakaki PhD. Student, Department of

Removable Prosthodontics,

Faculty of Dentistry, Hama

University, Syria

\section{A comparative evaluation of shear bond strength between self-cured resilient liner and denture base resin with different surface treatments}

\author{
Dr. Hala Sala Aldeen Alshakaki and Dr. Hussein Ali Al-Essa
}

DOI: https://doi.org/10.22271/oral.2020.v6.i3j.1026

\section{Abstract}

Statement of problem: Soft denture liners are widespread materials used in prosthetic dentistry. Their mechanical properties have to meet several key requirements such as adequate bond to denture base resins in order to provide right function of masticatory system and oral hygiene.

Purpose: To evaluate and compare the shear bond strength between a commercially available self-cured silicon-based liner and polymethyl methacrylate (PMMA) denture base resin with different surface treatments.

Materials and Methods: A soft denture liner Ufi-Gel P (silicone-based liner) and polymethyl methacrylate denture base resin (Rodex) were chosen for this study. A total of 50 samples were made, the samples were divided into five groups, containing 10 samples each. Group I: Consisted of an untreated surface of polymethyl methacrylate which acted as the control. Group II: The polymethyl methacrylate surface was treated with Acetone. Group III: The surface of polymethyl methacrylate surface was treated with laser Er:YAG with three different pulses duration. The shear bond strength was examined by Instron Universal Testing Machine at crosshead speed of $40 \mathrm{~mm} / \mathrm{min}$. T-student test was used to analyze the data $(\alpha=0.05)$.

Results: There was a statistically significantly difference in shear bond strength between laser-treated and untreated specimens $(P<0.05)$. The $300 \mathrm{~mJ}$ laser treatment produced the highest mean shear bond strength $(P<0.05)$.

Conclusions: Laser irradiation produced significant surface texture changes of the denture base material and improved the adhesion between denture base and soft lining material. In addition, different pulses duration was found to effectively increase the strength of the bond.

Keywords: PMMA, soft denture liner, Er: YAG laser, shear bond strength

\section{Introduction}

Soft denture lining materials have been used in dentistry for more than a century; the earliest soft liner was the soft natural rubber and it was applied by Twichell in $1869^{[1]}$. One of the first synthetic resins developed in 1945 as a soft liner was a plasticized polyvinyl resin ${ }^{[2]}$, followed by the introduction of silicones in $1958^{[3]}$.

Permanent soft denture liners have been a valuable asset for dentists. Because of their viscoelastic properties ${ }^{[4]}$, they help in providing an even distribution of functional loads on the denture-bearing area, thus avoiding local stress concentrations and also improving the retention of the dentures by engaging undercuts ${ }^{[5]}$. These materials are used for management of sore or atrophied mucosa, traumatic ulceration, and for obturators after maxillofacial surgery. Denture liners have several problems associated with their use such as the loss of softness, colonization by candida albicans, porosity, poor tear strength, and various degrees of softness. One of the most serious problems with soft denture liners is the failure of adhesion between the soft denture liner and the denture base ${ }^{[6]}$. Bond failure also creates a potential surface for bacterial growth, plaque, and calculus formation. Thus, it becomes imperative that the bond strength of the soft lining material to denture base be optimized by different mechanical and chemical surface treatments ${ }^{[7]}$. 


\section{Materials and methods}

The resilient denture lining materials involved in this study was auto polymerization silicon-based soft lining material [Ufi-Gel P Voco, Germany), and the denture base material was heat-curing acrylic resin [RODEX, Mulazzano (LO), Italy]. Rectangular wax patterns were used to made the shear specimens with a dimension of $(50 \cdot 10 \cdot 3) \mathrm{mm}$. The denture lining material was bonded to two plates of acrylic resin (Fig. $1)$. The samples were divided into five groups $(n=50)$ according to the type of surface treatment:

Group N: No treatment (control group)

Group AC: Surface treatment using acetone $30 \mathrm{~s}$.

Group L: Er:YAG laser irradiated: Bonding surfaces of the specimens were irradiated by Er:YAG laser (KaVo KEY Laser 3 1243/Germany).

Group L1: It is the group exposed to first degree laser irradiate $/ 1 /$, where the test surface is fully exposed to a laser irradiate pulse at $10 \mathrm{~Hz}, 100 \mathrm{MJ}$.

Group L2: It is the group exposed to second degree laser irradiate / 2 /, where the test surface is fully exposed to a laser irradiate pulse at $10 \mathrm{~Hz}, 200 \mathrm{MJ}$.

Group L3: It is the group exposed to third degree laser irradiate $/ 3$ /, where the test surface is fully exposed to a laser irradiate pulse at $10 \mathrm{~Hz}, 300 \mathrm{MJ}$. (Fig. 2)

The acrylic resin plates were then immersed in Silicone Putty (Zetaplus, Zhermak, Italy), together with wax spacers (10 $\cdot 10$

- 3) $\mathrm{mm}$ to provide space for the soft lining material after their removal (Fig. 3). The acrylic specimens surface was cleaned and wiped with a cotton tip wet with alcohol and allowed to dry, and then the adhesive was applied using the brush cover supplied with the adhesive and wipe over the entire specimens surface to which the soft lining material will be applied and left for a minute. After applying the adhesive, the soft lining material was prepared by mixing two equal lengths of the base (red) and the accelerator (blue) for 30 seconds to obtain a uniform consistency and then applied it to the test surface of the specimens. The soft lined material was left for 5 minutes until hardening. After hardening, the extra material was removed using a sharp scalpel after 10 minutes since application of the material.

The soft lining material was polished using a Glaze, where a drop of the base was mixed with a drop of accelerator and brushed on the soft lining and the acrylic edges and left for 10 minutes to dry at room temperature, and then specimens were stored in distilled water at a temperature of $37^{\circ} \mathrm{C}$ for a week. The samples were tested by using the universal testing machine (Fig. 4). Samples were tested at a crosshead speed of $40 \mathrm{~mm} / \mathrm{min}$ until the liner material was separated from the acrylic plates. The maximum force indicating the point of failure by separation was recorded. Surfaces of bond failure were evaluated by using an explorer for determining the type of failure (cohesive or adhesive).

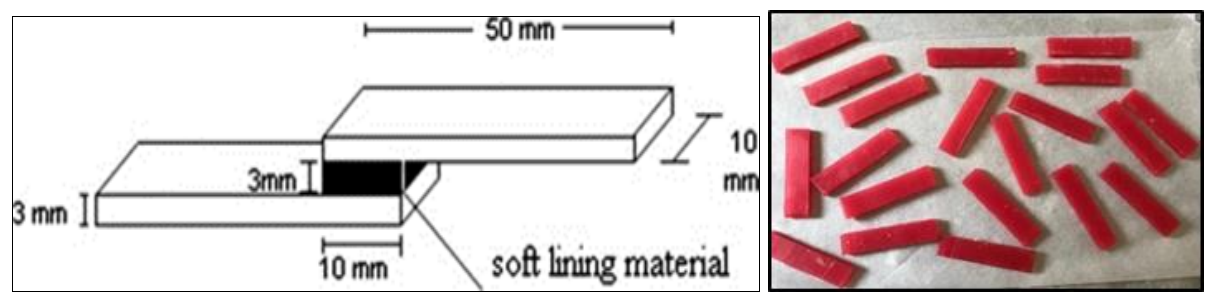

Fig 1: Specimen preparation

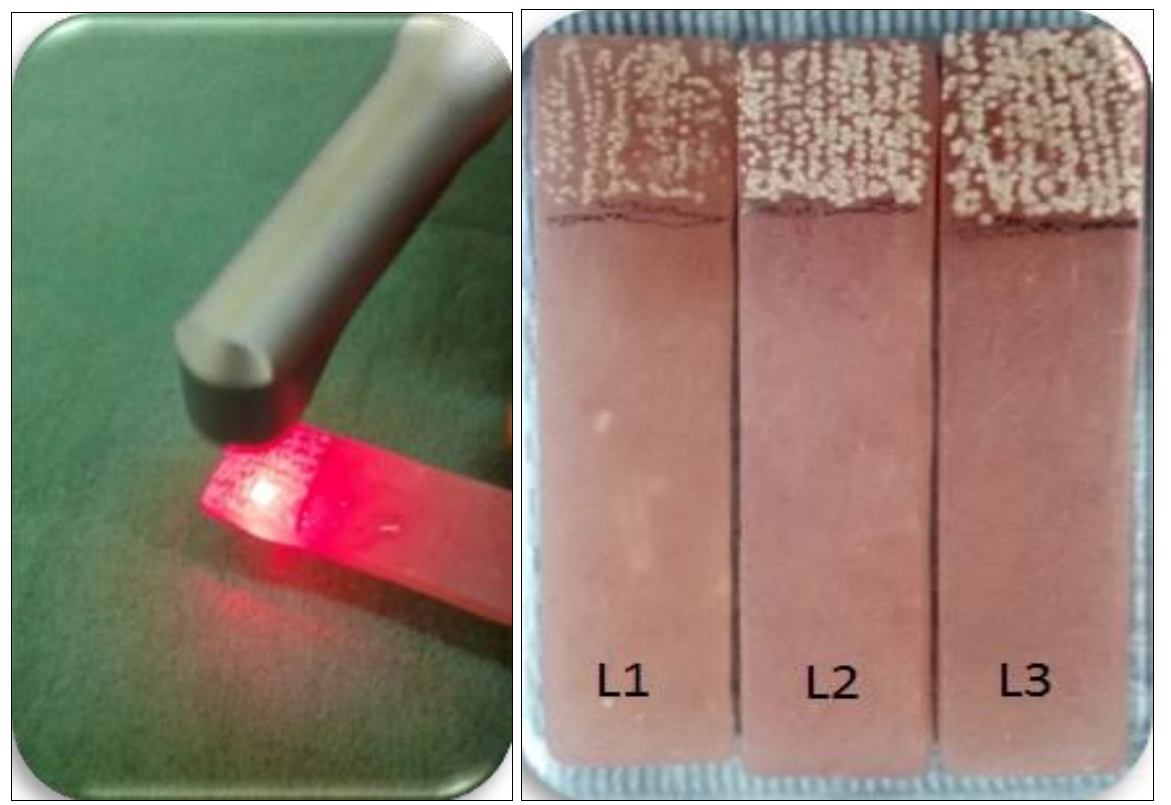

Fig 2: Appling laser irradiation on the bonding surface of the specimens 


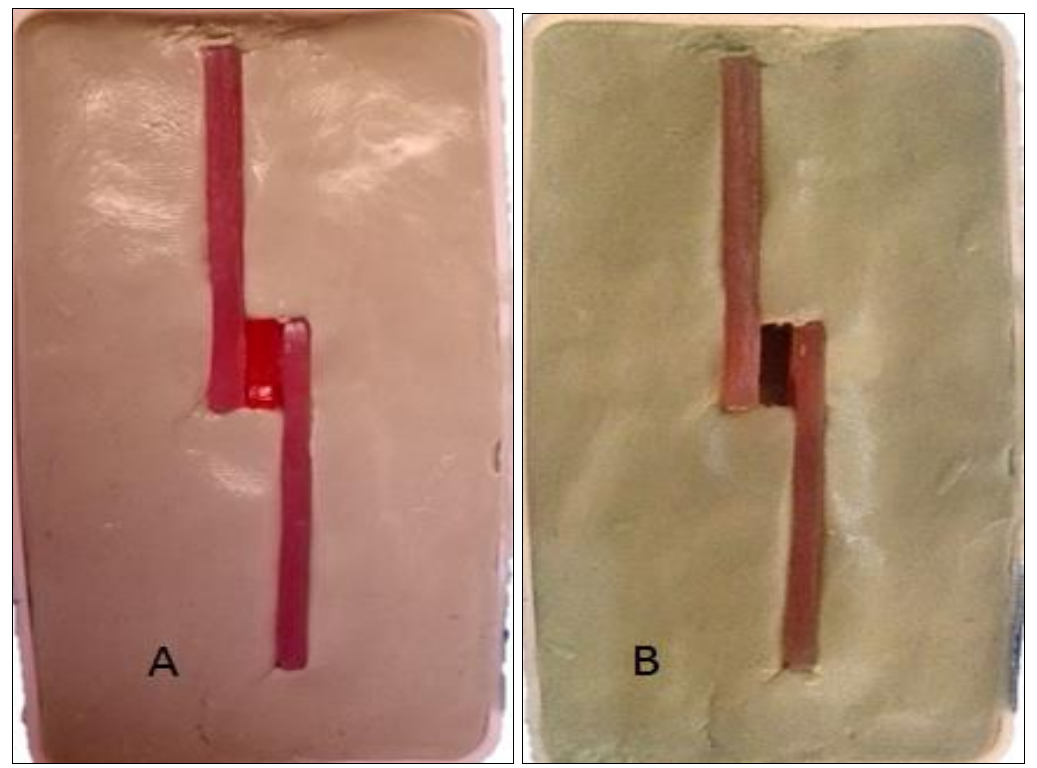

Fig 3A: immersing the acrylic resin plates with the wax spacer in the silicon rubber, B: removing the wax spacer.

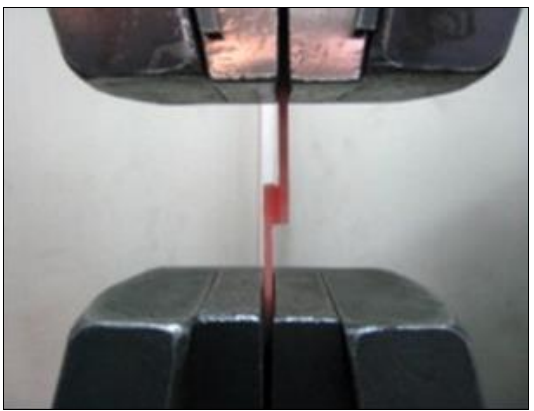

Fig 4: testing the samples by using the universal testing machine

\section{Results}

The mean shear bond strength values, standard deviations, and the type of bond failure of different surface treatments are presented in Table 1. The highest mean force value is observed in group L3 specimens while the lowest shear bond strength observed in group $\mathrm{N}$. We also note that there are no statistically significant differences between acetone group and control group $(p<0.05)$, while group L appears to have the highest values. As for the comparison between the laser groups, the group of L3 showed the highest value with statistically significant differences $(p<0.05)$.

Table 1: Mean shear bond strengths (MPa), standard deviation and the type of bond failure of different surface treatments of PMMA bonded to resilient lining material.

\begin{tabular}{|c|c|c|c|c|}
\hline Surface treatment & $\begin{array}{c}\text { Mean shear bond strength } \\
(\mathbf{M P a})\end{array}$ & $\begin{array}{c}\text { Standard } \\
\text { deviation }\end{array}$ & $\begin{array}{c}\text { Mean Type of failure } \\
(\boldsymbol{\%} \text { Coh })\end{array}$ & $\begin{array}{c}\text { Mean Type of failure } \\
(\boldsymbol{\%} \text { Adh) }\end{array}$ \\
\hline N & 0.82 & 0.15 & 0.01 & 0.99 \\
\hline AC & 0.84 & 0.18 & 0.02 & 0.99 \\
\hline L1 & 1.22 & 0.35 & 0.02 & 0.98 \\
\hline L2 & 1.58 & 0.34 & 0.03 & 0.97 \\
\hline
\end{tabular}

\section{Discussion}

Failure of the bond between PMMA and resilient lining materials have been a significant reason for the limited use of soft lined dentures ${ }^{[8]}$. To solve this perplexing problem, researchers have considered altering the PMMA surface before applying the resilient material ${ }^{[9]}$.

Because lasers are becoming more prevalent in the dental profession, they have been used to alter the surface of the PMMA with the intention of providing increased surface area and mechanical locks. Theoretically, both manipulations (increased surface area and mechanical locks) should benefit the bond site and result in stronger bonds ${ }^{[10]}$.

Shear test specimens of this study were based on the simple lab design described by Al-Athel and Jagger ${ }^{[11]}$. Evaluation of bond strength was carried out with shear bond tests, because the forces that the lining material is clinically exposed to are more closely related to shear and tear tests ${ }^{[12]}$. However, the shear test is a widely adopted test to assess the bond interface and simulates the clinical environments better than tensile force ${ }^{[13,14]}$.

The results of this study indicated that the force for failure was higher than $0.54 \mathrm{MPa}$ for all types of surface treatment. It has been reported that $0.45 \mathrm{MPa}(4.5 \mathrm{~kg} / \mathrm{cm} 2)$ would be satisfactory for clinical use of the resilient lining materials ${ }^{[15]}$. Considering this only criterion, the soft lining material (UfiGel P) was acceptable for clinical use.

The results of the present study showed that the surface treatment of the PMMA with the Er: YAG laser significantly increased the bond strength between the PMMA / soft liner specimens. While, it was found that applying acetone to the denture base resin did not affect the bonding strength of the soft liner material with the denture base resin, compared with the control group as it did not give statistically significant differences. In a study by Tugut et al. ${ }^{[16]}$, it was stated that treatment with Er: Yag laser with long pulse duration $(300 \mathrm{~mJ})$ shows the highest value of bond strength. In addition, long pulse treatment gives higher bonding strength than short duration pulse treatment. Thus, he found that laser treatment with different pulses duration and energy levels effectively increased the bond strength, and this is consistent with the results of our current study. While Gundogdu et al. [17] reported that treatment with the Er: YAG laser did not 
increase the bond strength between the soft liner material and the denture base resin. Although in our study, the Er:YAG laser at long pulse duration $(300 \mathrm{~mJ})$ increased the bond strength of soft lining material. In Gundogdu study they used an Er: YAG laser at a power setting of $150 \mathrm{~mJ}$, which may explain the different results.

These results can also be explained by the high energy of the Er: YAG laser, as this high energy causes instant evaporation of water along with volumetric expansion of the acrylic resin. This leads to ablation of the surrounding materials and increase in its surface area. Thus, the soft liner material penetrates into these created irregularities or spaces produced by the Er: YAG laser, thus increasing the bond strength ${ }^{[18]}$. Zhang et al. ${ }^{[19]}$ found that when using acetone and monomer MMA in the treatment of the surface of denture base resin, there were no significant differences between surface treatment with acetone and monomer MMA compared to the control group, and this is consistent with the results of our study. While in a systematic review by Muddugangadhar and colleagues ${ }^{[20]}$, it was stated that various surface treatments, including (acetone, and laser) improve the bond strength between the soft liner material and the denture base resin.

As this does not agree with our study, and this may be due to the different environmental conditions for the test procedure and the different type of soft liners and dentures base resin.

\section{Summary and Conclusions}

\section{Within the limitations of this study}

1. Laser pretreatment, is an effective way for increasing the shear bond strength between denture base resin and resilient soft liners, as the higher of the pulse duration $(300 \mathrm{~mJ})$ the higher of the value of bond strength.

2. The surface treatment of the denture base resin with chemical (Acetone) does not significantly affect the shear bond strength value of the soft liner material with the denture base resin.

\section{References}

1. Qudah S, Harrison A, Huggett R. Soft lining materials in prosthetic dentistry: a review. Int. J Prosthodont. 1990; 3:477-83.

2. Matthews E. Soft resin lining for dentures. Br Dent J. $1945 ; 78: 140$.

3. El-Hadary A, Drummond JL. Comparative study of water sorption, solubility, and tensile bond strength of two soft lining materials. J Prosthet Dent. 2000; 83:356-61.

4. Emmer TJ, Vaidynathan J, Vaidynathan TK. Bond strength of permanent soft denture liners bonded to the denture base. J Prosthet Dent. 1995; 74:595-601.

5. Lytle RB. Complete denture construction based on a study of the deformation of the underlying soft tissue. J Prosthet Dent. 1959; 9:539.

6. Winkler Sheldon. Ed. Essentials of complete denture prosthodontics. Philadelphia. WB Saunders Co, 1979, 130.

7. Kawano F, Edward R. Comparison of bond strength of six soft denture liners to denture base resin. J Prosthet Dent. 1992; 68:368-71.

8. Wright PS. Composition and properties of soft lining materials for acrylic dentures. J Dent. 1981; 9:210-23.

9. Craig RG, Gibbons P. Properties of resilient denture liners. J Am Dent Assoc. 1961; 63:382-90.

10. Jacobson NL, Mitchell DL, Johnson DL, Holt RA. Lased and sandblasted denture base surface preparations affecting resilient liner bonding. J prosthet Dent. 1997;
78:153-8.

11. Al-Athel MS, Jagger RG. Effect of test method on the bond Strength of silicone resilient denture lining material. J Prosthet Dent. 1996; 76:535-40.

12. Takahashi Y, Chai J. Assessment of shear bond strength between three denture reline materials and a denture base acrylic resin. Int. J Prosthodont. 2001; 14:531-5.

13. Mutluay MM, Ruyter IE. Evaluation of adhesion of chairside hard relining materials to denture base polymers. J Prosthet Dent. 2005; 94:445-52.

14. McMordie R, King GE. Evaluation of primers used for bonding silicone to denture base material. J Prosthet Dent. 1989; 61:636-9.

15. Kulak-Ozkan Y, Sertgoz A, Gedik H. Effect of thermocycling on tensile bond strength of six silicone based, resilient denture liners. J Prosthet Dent. 2003; 89:303-10.

16. Tugut F, Akin H, Mutaf B, Akin GE, Ozdemir AK. Strength of the bond between a silicone lining material and denture resin after Er: YAG laser treatments with different pulse durations and levels of energy. Lasers Med Sci. 2012; 27:281-5.

17. Gundogdu M, Yesil Duymus Z, Alkurt M. Effect of surface treatments on the bond strength of soft denture lining materials to an acrylic resin denture base. J Prosthet Dent. 2014; 112:964-71.

18. Akin H, Tugut F, Guney U, Kirmali O, Akar T. Tensile bond strength of silicone-based soft denture liner to two chemically different denture base resins after various surface treatments. Lasers Med Sci. 2013; 28:119-23.

19. Zhang Y, Zhang HQ, Ma JC, Jin SY. Effect of Surface Pretreatment with Chemical Etchants on Bond Strength Between a Silicone-Based Resilient Liner and Denture Base Resin, Zhonghua Kou Qiang Yi Xue Za Zhi /Chinese journal of stomatology. 2011; 46(12):762-4

20. Muddugangadhar BC, Mawani DP, Das A, Mukhopadhyay A. Bond strength of soft liners to denture base resins and the influence of different surface treatments and thermocycling: A systematic review, J Prosthet Dent. 2019; 123(6):800-806.e6. 